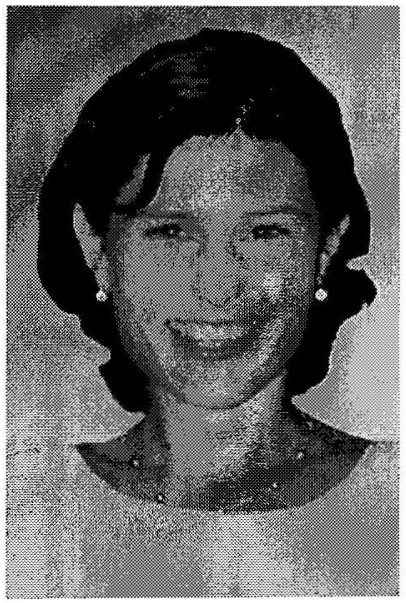

\title{
THE NEW "OFFICE TEMP": ALTERNATIVE MODELS OF CONTINGENT LABOUR
}

\author{
Petricia Alach and Kerr Inkson \\ Dept of Management \\ and International Business, Massey \\ University, Albany
}

Email k.inkson@massey.ac.nz

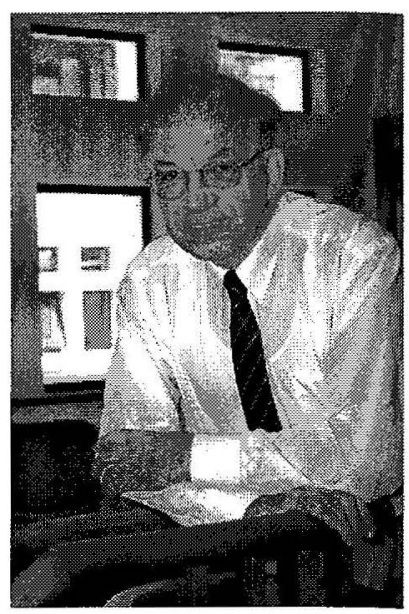

\begin{abstract}
Office temps are contingent workers, predominantly female, with secretarial and administrative skills, who hire their services out through an agency to client organizations requiring temporary labour. As organizations face changes in demand and workload, and seek flexible rather than stable structures, 'temping' is increasing in prevalence and importance, and is being used for increasingly skilled and responsible work. Understanding the work orientations and attitudes of temps is of value to employers, agents, and policy makers. Past studies and prevailing discourse on contingent labour suggest a somewhat negative picture of the temp as a member of the secondary labour market, and as a marginalized and insecure victim unable to secure a firm foothold in the economic marketplace. This study suggests a somewhat different picture.
\end{abstract}

\section{Introduction}

'Temping' is the commonly-understood term for temporary work which is clerical in nature. It is undertaken almost entirely by women. 'Temps' (those who do the temping) can be procured in two ways; through direct hire ${ }^{1}$ and via Temporary Recruitment Agencies.

This study focused on temps employed through temporary recruitment agencies. Utilising temps through these agencies enables end-user firms to utilise temporary staff as and when required without having to employ them directly, without having to take the time to advertise, interview and select a suitable individual, and without incurring the long-term commitment to, and costs of, permanent employees. The agency recruits potential "candidates', on an on-going basis and screens, tests and sometimes trains them to ensure that they are suitably skilled and ready for immediate deployment to client organisations.

The temp is legally employed by the agency, which invoices the client organisation for the hours she has worked, and pays her wages and other associated benefits ${ }^{3}$ as agreed. Hourly rate, conditions of work and length of assignment may all vary across assignments. Agencies are not required to give any guarantee of on-

\footnotetext{
${ }^{1}$ Directly hired in by firms as required without the use of a recruitment agency or other mediating organisation.

${ }^{2}$ Industry term for those employed by the agency as temps

${ }^{3}$ Special leave, sick pay, holiday pay etc.
}

going work (RSCA Report, 2000). Because of this, many temps co-register with multiple agencies and may be technically employed by different agencies across a variety of assignments during the time they are temping (RSCA Report, 2000).

Recent reports suggest that the use of temporary workers has become an integral part of the human resource practices of many businesses. Commentators have observed a structural shift in the way temporary labour is being utilised in contemporary firms (Carre, 1992; Nollen, 1996; Richards, 2001). Temporary workers are no longer used just as 'fill-in' labour or as a stop-gap measure related to changes in the business cycle. Instead, temporary staff nowadays fill positions of greater responsibility and are often placed in roles that are critical to business success. In response to this, analysts observe a rapid expansion in the temporary recruitment industry to accommodate the increased demand for temporary staff (Richards, 2001; Peck \& Theodore, 1998; Appelbaum, 1992). In the USA recruitment through temporary agencies accounted for one-fifth of all new jobs created since 1984 (Peck \& Theodore, 1998) and the temporary recruitment industry expanded 10 times as fast as overall employment between 1982 and 1990 (Appelbaum 1992). On any given day, members of the New Zealand Recruitment Services and Consulting Association (RSCA) employ approximately 8,000 agency-affiliated temporary employees (RCSA, 2000). However, this figure does not cover many other temporary clerical employees in New Zealand, including independent contractors and those placed by agencies not affiliated to the RCSA. In addition, many other sectors of the 
economy such as cleaning services, nursing, and supply teaching, are heavily dependent on temporary labour.

There has also been a shift in the type of work undertaken by temporary workers. Temporary staff nowadays fill positions of greater responsibility and are often placed in roles that are critical to business success (Brogan, 2001). Administrative/Clerical work continues to be the largest source of temporary employment, but in response to changing organisational demands the temping industry is diversifying into non-traditional markets such as industrial and medical temping (Carre, 1992) information technology, sales and marketing (Richards, 2001) and increasingly high level 'executive contracting', reported to be the biggest growth area in temporary employment (Richards, 2001; Shopland, 2001).

\section{Critical Issues}

In the past decade, a number of analysts have raised concerns over the outcomes of the increased use of temporary staff. These concerns relate both to the material conditions associated with this form of employment and the social and psychological implications of being 'a temp'. Most authors report that temping is typically an employment arrangement involuntarily entered into and that the majority of temps are seeking full-time, permanent employment (Gottfried, 1992; Smith, 1993; Rogers, 1995; Henson, 1996; Vosko, 2000; Hardy, 2000). Concerns have been raised over the way temps are marginalized, isolated and exploited in their dealing with recruitment agencies and client organisations.

Much commentary on temporary workers raises concern that temporary workers are economically disadvantaged and marginalised within the labour market. Because social and labour legislation continues to be premised on the assumption of 'the worker' as full-time, permanent and with a single employer, temps are often subject to reduced protection (Appelbaum, 1992; Carre, 1992). It is often reported that temporary workers are typically paid less than regular core employees and receive fewer benefits (Segal \& Sullivan, 1997, Nollen, 1996). In the United States especially entitlement to benefits such as health insurance and pension plans is often tied to length of service eligibility requirements (Garsten, 1999; Henson, 1996; Nollen, 1996). Because turnover in the temping industry is very fast (Henson, 1996; Nollen, 1996; Peck \& Theodore, 1998), temps often fail to qualify. Moreover, many temps are often unaware of their eligibility with regard to certain benefits and lack access to accurate, independent advice on their rights as temporary employees (Carre, 1992; Gottfried, 1992).

In addition to the concerns raised over the material conditions of temping, many commentators have drawn attention to social and psychological costs attributed to temping. In particular critics are concerned over the impact on an individual temp's sense of self worth when continually identified and interacted with as 'the temp'. Concerns are raised that pejorative notions of the temp as a form of sub-worker, may become internalised by those working as temps exacerbating experiences of alienation from self and others at work (Rogers, 1995). Observers report that negative attitudes to temps are still apparent in contemporary organisations and that this contributes to a climate of suspicion and distrust between permanent staff and temps (Smith, 1993; Rogers \& Henson, 1997; Richards, 2001). Commentators argue that temps are often socially isolated and marginally positioned within client organisations while on assignment. They note that temps are often spatially separated from permanent workers (Smith, 1998) or rendered "interactionally invisible" (Rogers, 1995, p. 151) by permanent workers who "actively create barriers of silence, space or regulation" (McAllister, 1998, p. 227).

Concern is also raised over the way temps are required to function in a relationship of extreme dependency on their agency. Temps are constantly monitored by their agency, usually via regular phone calls from supervising consultant to client, and through end-of-assignment feedback reports. Temps are seldom privy to this feedback and a 'good' report is typically inferred by continued offers of work. Observers argue that temps are marginalized in the placement process because they are not consulted over how placement decisions are made and that their preferences are seldom taken into account (Rogers, 1995; Gottfried, 1992; Henson, 1996).

\section{New Zealand Studies of Temping}

Little research into temporary employment has been carried out in the New Zealand context (RCSA Report, 2000, Marshall, 2001) with no published studies to date, being carried out exclusively on office temping.

In a Masters' thesis, Hardy (2000) surveyed temporary employees in a range of industries and occupations in Palmerston North. She utilised a self-administered questionnaire with questions focused around the reasons people had started to temp and what they perceived to be the advantages and disadvantages of this way of working. Findings confirmed much of the published literature. The primary reasons for starting to temp was typically the need to earn money while looking for a permanent job and the desirability of flexible work hours. The main perceived advantages were the flexibility of work and the variety of organisations and roles available to temps. The main disadvantages were the financial insecurity and uncertainty associated with temping. The majority of those surveyed would have preferred to be in a permanent job.

The findings of this study, though valuable as a contribution to the growing literature on temporary employment in New Zealand, are limited in terms of exploring some of the experiential aspects of temping. Additionally, the study did not distinguish between different types of temporary employment - for example, different occupational groups - making it difficult to determine whether there are differences in the experiences of those temping in different fields, for 
example whether industrial temping is experienced differently to office and/or medical temping.

A study by Inkson, Heising, and Rousseau (2001), of highly-qualified "leased executives" - managerial temps - showed contrasting results. These authors reported that leased executives used temporary assignments proactively to broaden their range of saleable skills and develop their reputations and networks. Other recent studies (Firkin, McLaren, Spoonley, de Bruin, Dupuis, Perera, Cremer, and Overton, 2002) signal a variety of reasons that individuals choose to engage in non-standard and temporary type work, including a greater sense of autonomy and control over when and where they work as well as the ability to better manage work in life. These studies suggest that alternatives may exist to the classic "marginalised temp" stereotype.

The current study builds on work begun in 2001, as part of a Masters' thesis, looking at the experiences of women clerical temping in New Zealand (Alach, 2001). That thesis was based on in-depth interviews with twelve women working as clerical temps, and two industry representatives who provided background information on the temping industry in New Zealand. Key findings in this thesis also disputed the dominant discourse, found primarily in the North American and European literature, of temp-as-victim, and questioned the extent to which temping is necessarily experienced as isolated or marginalized. The study also posited emerging alternatives including a kind of 'entrepreneurial temp' who chooses temping as part of an overall career strategy and a 'lifestyle temp' who chooses temping as a way of securing income to fund, and time to enjoy, family, social and leisure interests, and voluntary or community service.

\section{Research Objectives}

The current study sought to extend Alach's (2001) work by considering the orientations to work of a wider sample of female office temps. Issues included the effects of gender on the temp experience, the respective roles of employer and agency in temp management, the effects of economic cycles on temping, and the relationship of contingent work to family life. In this paper we consider especially the orientations of temps to their work, their temporary employee status, and their careers, and in particular the question of whether Alach's tentative findings on alternative models of temp self-identity could be supported in a wider sample.

\section{Methodology}

\section{Participants}

Acknowledging that the way in which participants were sought in the Alach (2001) study (word-of-mouth 'snowball' sample) may have led to idiosyncracies in the results, the current study sought to gather interviews from a broader range of women working as clerical temps.

In order to access as wide a range of experiences as possible, the researchers approached about twenty recruitment consultancies in Auckland directly and asked them to allow us to send a letter to women temping in clerical and secretarial roles for their agency asking them to participate in the study. Additionally the researchers secured support for the project from the Recruitment and Consulting Services Association (NZ) who placed an invitation to agencies to participate in the study in their quarterly newsletter. To date, eight agencies have participated in the study. This sample includes several of the largest temporary recruitment agencies in Auckland as well as medium and small sized agencies. To date, indepth interviews, each lasting about an hour, have been carried out with twenty-four temps and seven agency representatives.

The participants represented a broad range of temping experiences and life stories. Their ages ranged from 21 to 61 years of age with representation from temps who are married, single, divorced, self-supporting, and with or without children and/or other dependents. Average hourly rate ranged from around $\$ 13$ to upwards of $\$ 20$ and the length of time participants had temped from two months to over fifteen years. Participants had worked in a variety of temp assignments ranging from simple data entry to high-level executive PA roles and span a range of public and private sector organisations and industries.

The seven agency representatives included representatives from the some of the largest recruitment agencies in Auckland, several medium sized agencies and a couple of smaller agencies. They had all worked in recruitment for several years, often in a variety of roles.

\section{Interviews}

The interviews carried out with the temps were semistructured with questions designed to draw the participants into discussion about their experience of work. The ordering of the questions varied over time to accommodate participant preferences and to allow participants to pursue the topics of most salient to them. Broadly speaking, the questions asked about the participants about their reasons for temping, relationship/s with temping agencies and what it was like for them, being a temp. Additionally they were asked for background information, specifically age, marital status, family situation and living arrangements. The interviews were tape-recorded and summarised for later analysis.

The agency representatives were interviewed in order to gather background information and insights into current and future trends in the temping industry, potential opportunities and threats, and their perceptions about the motivations, attitudes and behaviour of the women who their agency employed as temps. 


\section{Results}

These results are tentative, in that at the time of writing not all intended interviews are complete, and intended numerical analysis has not yet taken place.

\section{Preference for permanent or temporary work}

As in the Inkson et al (2001) and Alach (2001) studies cited above, results so far go some way towards providing an alternative to the dominant discourses which position temps as victims. The assumption that temping is always involuntary was challenged. In contrast to Hardy (2000) who found that over $90 \%$ of her sample of temporary workers would have preferred a permanent job, this study found that most of the office temps interviewed preferred not to have a permanent job, if they could be sure of regular, on-going temping work. Participants were wary of committing to a permanent job, mainly due to fears of getting bored and/or getting stuck in a specific situation. Several reported that if they had a permanent job they would miss the change and variety that working as a temp had afforded them.

"I don't like being tied down, I like being a free agent" (SL).

"that's probably what's stopping me from getting a permanent job because if you don't like a job temping you think 'oh it's only for 2 days or 3 weeks or 6 months but you think 'gosh if this was permanent I wouldn't want to be stuck here'...so I'm a bit hesitant to take the plunge" (IKW).

"I don't know about permanent cause that's sort of a scary thing. I can't imagine being with one company forever, I don't think people do that anymore" (MP).

Additionally, many participants made use of the on-off flexibility that temping afforded them and cited as a major benefit the opportunity to decide, sometimes on a day-to-day basis, whether they want to work

"It suits me, I can work when I want. If I don't want to work I can say no" (EH).

"I like temping, it gives me the flexibility to go off to the States for three months and if I had a permanent job I'd probably have to resign and lose my job if I wanted that length of time off but with temping I can just give a few week's notice and I'm free to go" (VH).

The majority of participants had made a conscious decision to start temping, albeit for a variety of reasons. Several participants, who were looking, ultimately, for permanent 'career' jobs, found that temping enabled them to make unhurried decisions about the types of role they considered.
“...I'm going through a non-committal, permanent work phase at the moment but do plan to look for a permanent job. I plan to be really fussy about it...so that's what I'm going to do and see what happens and if it doesn't happen and I'm still temping in a year, well so what!" (LA).

"I'm keeping an eye out for a permanent job if something really appeals to me but I'm not willy nilly applying for any old thing" (TW).

For others, the decision to temp had come out of a desire to reposition the place of paid work in their lives. For several participants temping brought with it a sense of being 'freed-up' to devote more time to family or leisure activities. This was brought about both through the onoff flexibility offered by temping and a shift in the way the women felt about their work, in particular the ability to "retain a certain distance from the work which you can't do as a permanent worker" (AJ).

"You don't really have to put your whole self in and you can just walk away at the end of the day and not be worried about it... and if I compare this job to my permanent job where you were just expected to stay late and put in the hours, I'm really enjoying the fact that at 5 o'clock I'm out the door, there's no waiting around for another ten minutes to do something, I'm just gone and that's very cool!" (MP).

Interestingly, and perhaps surprisingly, several participants reported that they preferred temp work because they perceived it to be less risky than a permanent job. Temp work was perceived as relatively easy to get: most participants reported that they had been given their first assignment within days, if not hours, of registering with an agency. Several participants contrasted this with the length of time it can take to get a permanent role and concluded that in this sense, temping, if work is plentiful, can often be a more reliable and secure source of income than many permanent jobs which under current employment conditions are always at risk of being made redundant.

"The main benefit is that it should be more sort of stable than permanent work because they should be employing you straight away whereas if you were a permanent person and you lost your job you'd have to spend a few weeks trying to find a new one whereas as a temp there might be a day" (MP).

"I can get temping work quickly and easily. I'm experienced in it. It's just the easy option really for me" (TW).

This was particularly so for some participants who were attempting to make a career in some of the more volatile industries, such as television.

"Temping's definitely been critical in allowing me to be because if it hadn't existed I would have had 
to chose an alternative profession, or gone back to study or compromised a lot in what I wanted to do..." (RJ).

\section{Temping and Self-Development}

Permanent work is popularly believed to provide permanent employees, committed to their organizations, with greater opportunities for development through the company's training and staff development systems. In contrast, temps are not seen as a responsibility in terms of development. However, several temps reported that the ability to 'move around' had contributed to their personal and professional development in the form of overcoming shyness and, 'firstdayitis', and developing self-confidence in dealing with different people and novel situations.

"You lose your fear of first days because you have so many first days. You don't get nervous and that's a good thing" (JJ).

"Now I can stroll into a new place, no worries about meeting new people or learning new processes at all...lay it on, I can totally handle it!" (LA).

Furthermore, exposure to a range of workplaces means that temps are constantly required to learn new systems and pick up different ways of working. This can contribute to the development of skills and other knowledge which can be of benefit to the temp, both in securing future assignments and also if applying for a permanent job.

\begin{abstract}
“As a temp you're always learning new things, not just about one thing but about different companies and different peoples, policies and everything so I see people that temp are very open minded" (GT).
\end{abstract}

"Temping teaches you how to learn, how to get to know and about being flexible, about being more confident, coping with being in new situations and how to ask for help" (SL).

The decision to continue temping was one that many participants had made despite experiencing economic hardship over recent months as a result of a downturn in the demand for temps. The results so far draw attention to the importance of contextual factors when considering the ways in which temping as a way of working is experienced.

\section{Temping and the Temp "Market"}

The 'marginalised temp' stereotype suggests that permanent work acts as a buffer for workers against periodic market downturns which leave temps exposed. The timing of the current study in comparison to that undertaken by Alach (2001) provide for interesting comparisons between the experiences of those temping in

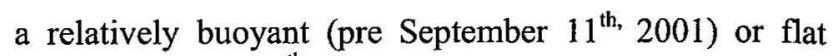
(post September $11^{\text {th }}$ ) market.

Pre September $11^{\text {th }}$, the temps interviewed by Alach (2001) reported little shortage of work, the ability to pick and choose assignments (within certain limits) and in many cases a problem of having 'too much work' and being unable to achieve the lifestyle improvements they had anticipated when becoming a temp. Such experiences of being in 'too much demand' were confirmed at that time by industry representatives who reported on a severe shortage of 'good temps' in the Auckland market.

In contrast respondents in the current study overwhelmingly reported that post September $11^{\text {th }}$ the market for temps had dried up with many temps experiencing a severe lack of assignments, particularly in the fourth quarter of 2001 and the first quarter of 2002. This was experienced by the temps, both in terms of having no assignments for weeks, or in some cases months, and in terms of experiencing a difference in the types of assignments being offered - typically shorterterm, lower-level and paid at a lower rate. Agency representatives confirmed this trend, reporting that client organisations had become much more conservative in their 'temp spend' and were seeking to provide temporary cover through internal 'reshuffling' rather than through using agency temps. Despite this, very few participants were actively looking for permanent work, and of those who were the majority cited a desire to offer their commitment to a more exciting and challenging role, rather than financial imperatives as their primary motivators. This suggests that for many temps, the condition of contingent employment has become the anticipated and preferred backdrop to their lifestyle, regardless of external labour market forces.

\section{Temping and Social Isolation}

A further critique in the 'marginalised temps' literature is that temps are socially isolated. However, few participants reported problems with the 'people side' of temping: most reported that the people they had met on assignment had been really nice and helpful. Exceptions to this were generally experienced in short-term, one-day reception roles, which were overwhelmingly reported as the 'least favourite' of temp assignments. There was some reference to negative perceptions of temps that had been encountered in the workplace but no evidence to suggest that these participants had internalised any such stereotypes. The general response of participants to such encounters was extremely dismissive with perpetrators being described as outdated and ignorant.

\section{Temping and Career Prospects}

Despite the subjectively-experienced positive features of temping documented above, the perception that temping is always involuntary and never a 'proper' job appears to continue to prevail in society at large. Participants reported their sense that the decision to temp, though 
increasingly coming to be seen as a legitimate 'lifestyle' choice, continues to be viewed as either a 'bad' or noncareer choice. This was expressed, most poignantly, by those temps looking to move into permanent, 'career' type jobs. These women were wary of how extended period of temping may be interpreted by prospective employers.

"I'm having difficulty getting the job I want because I'm seen as slightly erratic, slightly unreliable and unfocused" (GG).

"all of my work history has been temping and I think that makes it difficult because I don't have a solid history in one place. I think that makes my permanent work search quite difficult" (EC).

However much temping may suit those who do it in their current circumstances, therefore, most consider that if they want eventually to move either to permanent work or to positions carrying higher responsibility, they need to be careful not to allow too many years to go by in temporary positions. However, this is attributed more to employer and societal prejudices against temping than to any inherent defect of the temping experience or of those who do it. The effect of this perceived bias is mitigated by the fact that many temps have no intention, even in the longterm, of taking up permanent jobs not of seeking traditional career 'advancement', but prefer to maintain the non-central position of non-central employment in their lives.

\section{Discussion}

This findings of this study begin to provide alternative models to predominant accounts of contingent workers. The majority of reports focus on the ways in which the availability of temp work is contingent on organisational whims and economic fluctuations. While we acknowledge this to be true for many contingent workers, we seek to question the extent to which working as part of the contingent workforce, in this case as a clerical temp, is necessarily imposed on individuals by external forces rather than being a choice made by individuals who have available to them a wide range of work options. The extension of temporary forms of work to larger numbers of people and a wider range of occupations are doubtless important factors in enabling more self-confident and proactive individuals to frame temporary work to suit their needs rather than seeing it as 'employment of last resort'.

In this sense then, we introduce the notion that research into 'contingency' in relation to paid work should seek to understand both the ways in which the availability of work is contingent on economic and organisational imperatives and also the ways in which individual decisions about whether to take on such work is contingent on other life priorities. Such research is particularly important before we begin making sweeping assumptions about the extent to which being part of the contingent workforce is necessarily experienced as good, bad or otherwise and by whom.

Reports from participants suggest that, despite attempts by academics to broaden concepts of career to encompass aspects of life other than paid work, employers still think of 'career' in a narrow, permanent-employment focused way. Moreover, conventional industrial couplings, such as equating 'length of time served' to 'value of contribution', appear to prevail, much to the chagrin of those temping. The majority of agencies seem to agree, with many respondents, both temps and consultants, reporting their feeling that an extended period of temping 'doesn't look good on paper'.

This presents an interesting paradox as contemporary workers are increasingly called upon to display an ability to adapt and the desire to 'embrace change' - however, these reports would suggest, not too much. It may also be that the nature of the temping, i.e. predominantly low status clerical work, mediates the perception of those who chose to do this work as temps. Are leased executives, for example, perceived as having 'commitment issues', rather than a healthy desire for change and new challenge? Does an unconscious sexism inform different expectations of predominantly female office temps and predominantly male managerial and IT temps? It is important to note that these perceptions of how temps 'look on paper' to potential employers are forwarded by the temps themselves and their consultants. It would be interesting to research employer perceptions of individuals with so called 'chequered' work histories to determine the way in which this is interpreted and responded to.

Research such as this contributes to many contemporary academic conversations. Firstly, by providing first-hand, in-depth reports from those working as temps, this research provides some insight into the lived reality of temps; and highlights both the positive and negative aspects of this experience. This in turn can be useful in signalling to politicians and policy makers, areas of potential harm, which may be minimised through legislative and regulatory means.

Secondly, this research, and in particular the questions it raises around conventional understandings of contingent work, contributes to broader academic and popular debates which seek to understand the ways in which people's relationship to paid work is changing and the implications of this in terms of the continuing centrality of paid work in individual constructions of identity and the degree to which conventional industrial couplings are being challenged.

As more people in a diverse range of industries come to experience employment as contingent and impermanent, research which explores the ways in which paid work retains or reduces its centrality in individual lives is important. Research is needed which draws attention to communalities in the experience of contingent workers and signals to policy makers and politicians areas of potential harm or opportunity. Equally important is work 
which pays attention to the differences experienced by contingent workers and which seeks to develop new understandings of why and how individuals have been forced into, or have chosen to take up this kind of work.

To do so properly may necessitate a re-examination or even discarding of many of the implicit assumptions which have guided conventional academic discourses around the place of paid work in people's lives. For example, assumptions around what constitutes a 'good' job or a 'normal' career path may need to be re-examined. We might start with the question 'according to whom?'

\section{References}

Alach, P. 2001, "Being a Temp: an exploratory study into the experiences of women clerical temps in New Zealand", Master of Commerce thesis, Department of Management and Employment Relations, University of Auckland.

Appelbaum, E. (1992). Structural Change and the Growth of Part-Time and Temporary Employment. In V. L. DuRivage (Ed.), New Policies for the Part-Time and Contingent Workforce. New York \& London: M.E. Sharpe.

Brogan, T. W. (2001). Scaling New Heights: ASA's Annual Analysis of the Staffing Industry. Staffing, May-June, 1-8.

Carre, F. J. (1992). Temporary Employment in the Eighties. In V. L. duRivage (Ed.), New Policies for the Part-Time and Contingent Workforce. New York \& London: M.E. Sharpe.

Firkin, P., McLaren, E., Spoonley, P., de Bruin, A., Dupuis, A., Perera, H., Cremer, R., Overton, J. (2002/1). Non-Standard Work: Alternative Working Arrangements Amongst Knowledge Workers. Labour Market Dynamics Research Programme, Albany and Palmerston North: Massey University.

Garsten, C. (1999). Betwixt and between: temporary employees as liminal subjects in flexible organisations. Organisation Studies, 20(4), 601617.

Gottfried, H. (1992). In the margins: flexibility as a mode of regulation in the temporary help service industry. Work, Employment \& Society, 6(3), 443460.

Gottfried, H. (1994). Learning the score: the duality of control and everyday resistance in the temporaryhelp service industry. In J. M. Jermier \& D. Knights (Eds), Resistance and Power in Organisations: Critical Perspectives on Work and Organisations (pp. 102-127). London: Routledge.

Hardy, D. (2000). A preliminary study of temporary employees in New Zealand: Who are the temps in Palmerston North, why are they temping, and what are their temping experiences like? Palmerston North: Unpublished Masters thesis, Department of Management Systems, Massey University.
Henson, K. D. (1996). Just a Temp. Philadelphia: Temple University Press.

Heynen, M. (2001). Temping in New Zealand. Personal communication, 31st August.

Inkson, K., Heising, A., and Rousseau, D. M. (2001). The interim manager: prototype of the 21 st century worker? Human Relations, 54(3), 259-284.

Marshall, P. (2001). Temping enquiry. Personal communication, 9 th October.

McAllister, J. (1998). Sisyphus at work in the warehouse: temporary employment in Greenville, South Carolina. In K. Barker \& K. Christiansen (Eds), Contingent Work: American Employment in Transition. Ithaca NY: Cornell University Press.

Nollen, S. D. (1996). Negative aspects of temporary employment. Journal of Labour Research, 17(4), 567-582.

Peck, J., \& Theodore, N. (1998). The business of contingent work: growth and restructuring in Chicago's temporary employment industry. Work, Employment \& Society, 12(4), 655-674.

Richards, M. (2000a). Temporary staff: facing an attitude time-warp. People and Performance, August 8-9.

Richards, M. (2000b). Temporary workers: thawing the attitude time-warp. People and Performance, October, 7-8.

Richards, M. (2001). The psychology of the temporary employment industry. Human Resources, August.

Rogers, J. K. (1995). Experience and structure of alienation in temporary clerical employment. Work and Occupations, 22(2), 137-166.

Rogers, J. K., \& Henson, K. D. (1997). 'Hey, why don't you wear a shorter skirt?': Structural vulnerability and the organisation of sexual harassment in temporary clerical employment. Gender and Society, 11(2), 215-237.

R.S.C.A. (2000). Submission on the Employment Relations Bill. Wellington: Recruitment and Consulting Services Association. 
Segal, L. M., \& Sullivan, D. G. (1997). The growth of temporary services work. Journal of Economic Perspectives, 11(2), 117-136.

Shopland, A. (2001). Stars in a temporary role. New Zealand Herald, 20/8/01.

Smith, V. (1993). Flexibility in work and employment: The impact on women. Research in the Sociology of Organisations, 11, 195-216.
Smith, V. (1998). The fractured world of the temporary worker: power, participation and fragmentation in the contemporary workplace. Social Problems, $45(4), 411-430$.

Vosko, L. F. (2000). Temporary Work: The Gendered Rise of a Precarious Employment Relationship. Toronto: University of Toronto Press. 